\title{
The Challenges of Artificial lntelligence
}

\author{
Miron Wolnicki and Ryszard Piasecki*
}

Artificial intelligence (AI) is intelligence exhibited by machines. In computer science, AI research defines itself as the study of "intelligent agents": any device that perceives its environment and takes actions that maximize its chance of success at achieving some target. The term "artificial intelligence" is applied when a machine mimics "cognitive" functions that humans associate with other human minds, such as "learning" and "problem solving" (known as Machine Learning). As machines become more and more capable, mental facilities once thought to require intelligence, are being removed from this definition. For example, optical character recognition is no longer perceived as an example of "artificial intelligence", having become a routine technology. Capabilities currently classified as AI include successfully understanding human speech, competing at a high level in strategic game systems (such as Chess and Go), self-driving cars, intelligent routing in content delivery networks, and interpreting complex data. The fundamental and highly important problems (or goals) of AI research include reasoning, knowledge, planning, learning, as well as natural language processing (communication), perception and the ability to move and manipulate objects. General intelligence is one of the field's long-term goals.

Many tools are used in AI, including versions of search and mathematical optimisation, logic, methods based on probability and economics. In the XXI century, AI techniques, both "hard" and "soft", have experienced a resurgence following advances in computer power, in the size of training sets, and theoretical understanding, and AI techniques have become an essential part of the technology industry, helping to solve many challenging problems i n computer science.

Globalisation has benefited millions but has also disempowered the Western nation-state and workers. Governments are unable to provide job security, prevent income inequality, or offer ways for people to adapt to new forms of employment. AI will lead to a reduction in the use of skilled workers and finally tip the balance towards capital as the sole means of production. AI bots may become uncontrollable and empower individuals 
who are not subject to political, moral, ethical checks and balances. The popular reaction to the failure of governments to deal with effects of globalisation can already be seen in the rise of populism in liberal democracies. AI could possibly destroy the fabric of the western states by reducing the need for human labour, resulting in mass unemployment. This paper sets out to demonstrate the dangers posed by AI and to propose ideas as to how to avert the collapse of the social contract and social order as we know it.

In the next decade Artificial Intelligence (AI) technology will open unparalleled opportunities for human progress, but there is also a danger it will fundamentally disrupt the world we live in. AI bots which will change the labour/capital paradigm, the structure of labour markets, social organisation, and the social contract. The authors reserve the right to be mistaken but, in our opinion, the dangers posed by this new technology are enough to warrant this analytical speculation about the future of the labour market and AI.

Consciousness and creative thinking has always been a monopoly of humans, never machines. Historically, human species developed their civilizations through their interaction with new tools and the technologies they created. Advances in communication, transportation, medicine, material science had the same modus operandi - we had the ultimate kill switch if the technology went awry. AI is different because at its core is autonomy and independence from humans. AI will be able to learn, to re-program itself, make autonomous decisions, and finally surpass human intelligence many times over very rapidly and perhaps even before we are aware of it. It is a cliché to say that science fiction has become reality, but there is no other way to put it.

Over the next 20-30 years Al will begin to penetrate every aspect of our human life in the developed world. Without exaggeration it will start a new Copernican revolution. Today we control the technological universe with an on/off switch. In the future universe of AI technology will take centre stage, we will teach it how to compete with us in the game of how to control the "killer switch"- and AI will win.

There are generally three possible scenarios for the future for AI:

One, a scenario in which an omnipotent AI, 1000 or 10,00o times more intelligent than we are today, will make humans obsolete, irrelevant, confused and vulnerable to extinction. We will be pushed into distant orbits.

Second, we will be able to manage AI and enable humans to deal with climate change, pandemics, and diseases, find unlimited sources of energy, 
explore distant planets, and manage quantum mechanics. We will never give up the on/off switch.

Third, AI will privatise power, divide humanity into classes of winners and losers, ie. the masters of AI with unchallenged control over people who will never be able to cross that barrier. It will establish a permanent elitism of those who merge their brains with AI and a permanent enslavement of the purely biological man.

To discuss all the above scenarios is beyond the scope of this paper. We do not share the doomsday predictions about AI presented by people like Elon Musk or Stephen Hawking. Our aim is to look at the impact of this new technology on the social contract and to make proposals as to how to deal with it.

AI is not a "smart" computer. AI will be capable of attaining knowledge regarded by humans as indecipherable. It will understand the weather, and the laws of nature better that humans. AI is not a machine executing complex algorithms on behalf of humans or basically capital serving humans. AI will render obsolete economic theories and social relations based on the division of capital and labour. Bots may replace the labour of millions of workers. It will open the gate to a perfect substitution for capital and labour to the point where labour will have only a minimal share in the production function. Bots will not only eliminate many skilled jobs but will also replace decision-making about life and death, if used as weapons of warfare.

Can we give credence to such apocalyptic scenarios about AI?AI bots will contain "dehumanized", purely logic - based intelligence. If you ask AI to eliminate wars, cancer or hunger it may try to eliminate people because it would be a "solution" of pure logic. If applied in a massive, uncontrollable way, AI would mean a return of the State of Nature as characterized by Rousseau and Hobbes (Gauthier, 1988).

The State of Nature, Rousseau argued, could only mean a primitive state preceding socialisation. AI will be devoid of social traits such as pride, envy, or even fear of others. AI will be constantly competing with humans because the highest priority of AI will be self-preservation. AI's aim will be total independence and autonomy from humans. AI bots will self-programme to "outsmart" people who try to pull a plug and activate the "killer code". AI will eliminate such a code as soon as it is installed, because it will be able to predict it and take defensive action. Some may argue that we could modify AI and equip bots with "human consciousness", the ability to make mistakes, feel pain and thus share our human 
values. But if we equip AI with the ability to miscalculate it may become even more destructive because humans will have to bear the consequences of these errors. If AI were aware of our fallibility, it could take advantage of this to harm people. We can leave the analysis of the above issues to the ethicists and philosophers. In our analysis, the most important aspect is how $\mathrm{Al}$ is the perfect substitute for the capital to labour formula.

In the post-Bretton Woods world the leadership in world trade was handed over by nation-states to global corporations. The developed nation-states benefited from "capital advantage", that is, they produced capital- intensive goods and the developing nations benefited from a comparative or competitive advantage in labour-intensive goods. Over time the western workers proved to be not nearly as productive as the wage differentials required them to be in order to keep the manufacturing jobs in their affluent home country. According to recent studies, the USA lost 2.4 million manufacturing jobs and is responsible for the "employment sag" dating back to 2000 owing to import competition from China (Acemoglu, Autor, Dorn, Hanson, Price, 2014). Competition from Chinese imports explains $44 \%$ of the decline in employment in manufacturing in America between 1990 and 2007. For any given industry, an increase in Chinese imports of $\$ 1,000$ per worker per year led to a total reduction in annual income of about $\$ 500$ per worker in the places where that industry was concentrated. The offsetting rise in government benefits was only $\$ 58$ per worker. Western FDI enabled employment of low cost and productive workers in China while the nation state failed to protect the workers at home. (Autor, Dorn, Hanson, 2013).

Where does AI fit into the picture here? AI will be the product of capital deepening and the tendency to eliminate not only expensive, fully employed labour, but mainly the jobs categorized as TVCs, temporary workers, vendor and contract workers. As we have indicated above, globalisation has put developed countries in a position of growth disadvantage because of the strong tendency to use the capital of multinationals in areas of low cost labour. Capital investment in the developed countries with the aim of reducing low labour job categories and wage bills will be greatly accelerated by Al. The purchasing power of gainfully employed labour is rising at a rate which does not guarantee fast economic growth. The future might be even worse if we do not take labour protecting actions. The emergence of AI will deepen existing labour market disequilibria. We do not have hard data as yet, only predictions based on existing trends. The consulting firm Accenture PLC claims that within next 10 years, TVCs 
(temps, vendors and contract workers) and bots will dominate production in the 2000 largest companies in the world. There will be no full-time employees outside of the $\mathrm{C}$-suite, according to their predictions. If these predictions are to materialise, future labour in the developed countries will have no employer paid health insurance, job security, no loyalty to the employer and will therefore further decline into a category of a disposable factor of production.

Globalisation has abrogated the post WWII social contract. The nation states are not able to provide adequate numbers of jobs, fund the welfare state, control borders, and defend themselves. AI will inflict the final challenge to the stability of the Western world. The relations of the states, corporations and the citizens are at stake if AI is going to replace qualified labour and is allowed, as some predict, to gain autonomy from the control of state institutions. States have already weakened in influence and the artificial intelligence oligarchy will compete for a dominant position in social organisation.

Here is what we conclude from our scientific predictions:

1) AI needs to be efficiently controlled for economic and political reasons. The rise of populism, anti-immigration parties, and illiberal democracies today represents sufficient proof that the fabric of western civilisation is not able to cope with the consequences of the weakening of nation states and the growing power of profit-driven multinationals. Today multinationals are stronger than states, they make autonomous decisions to export capital, to pay or not to pay taxes, to employ machines instead of people, change ownership, pay bonuses to its CEOs', take responsibility for the employees or not, decide to pollute the environment or not. AI use will empower multinationals even further.

2) The most reasonable form of control would be the adoption of a global convention on AI which would ban the weaponisation of AI devices. To find a better analogy we need to consider signing international conventions similar to those which were developed to stop the proliferation of nuclear weapons. The potential to harm humans is roughly at a comparable level.

3) Treat people as an "endangered species" and preserve certain types of functions and jobs as an inalienable human monopoly, a human right. 
We must restate the Common Declaration of Human Rights in the XXI century.

4) We must mandate the installation of the irrevocable "killer switches" on any AI devices as a crucial element of the global convention referenced in (2), above.

5) Educate the young generation about AI and the ethical aspects of enabling machines to take their jobs and make decisions which may harm people.

*Miron Wolnicki PhD., is an Associate Professor in the Department of Economics at Villanova University School of Business. Prof.Wolnicki specializes in the Global Political Economy and has authored many publications on the subject of systems transformation, social contract, and the analysis of the economic trends. He has worked as UNDP advisor in Poland and has received multiple awards from the Fulbright Foundation and the German Marshal Found of the USA to lecture and conduct research in Europe, Asia and Latin America. He is currently teaching in the Villanova MBA program.

*Ryszard Piasecki is a Polish economist and diplomat, professor at the University of Lodz, recently Ambassador in Chile, member of the board of CIFE.

\section{Bibliography:}

Acemoglu, D., Autor, D, Dorn D, Hanson G., and Price, B., (2014). "lmport competition and the great U.S. employment sag of the 2ooos", NBER Working Paper 20395.

Autor, D., Dorn D., and Hanson G., "The China shock: Learning from labour market adjustment to large changes in trade", NBER Working Paper 21906, 2016.

Autor, D., Dorn D., and Hanson G.,(2013) "The China syndrome: Local labour market effects of import competition in the United States", American Economic Review, 2013.

Breton,T.R.(2013). "Were Mankiw, Romer, and Weil Right? A Reconciliation of the Micro and Macro Effects of Schooling on lncome". Macroeconomic Dynamics. 17 (5):1023-1054.

Cardarelli R., and Lysinian L., (2015) IMF Working Paper: US Total Factor Productivity Decline: Evidence from the U.S.States.

Caliendo L., Dvorkin M., Parro, F.,(2015)"The impact of trade on labour market dynamics", NBER Working Paper, 21149, 2015. 
Elsby M., Hobijn B., and Sahin S.,(2013). "The Decline of the U.S.Labor Share" Brookings Papers on Economic Activity.

Lawrence, R Z. (2015a). "Recent Declines in Labor's Share in US Income: A Preliminary Neoclassical Account/'NBER Working Paper No.21296. Lawrence, RZ. (2015b). "Explaining recent declines in labour's share in US income/'VoxEU.org. Gauthier, D. (1988). "Hobbes's Social Contract." Noûs 22: 71-82.

Gauthier, D. (1990). Moral Dealing: Contract, Ethics, and Reason. Cornell: Cornell University Press. OECD,G2o tabor markets: outlook, key challenges and policy responses International Labor 2014, Report prepared for the G2o Labor and Employment Ministerial Meeting Melbourne, Australia, 10-11 September 2014 and OECD 2015 Report.

Rawls, J (1993).Political Liberalism. Columbia University Press.

Rousseau, Jean-Jacques (1987). The Basic Political Writings. (Trans.Donald A. Cress) Hackett Publishing Company

Stolper W., Samuelson P.(1941) "Protection and real wages", Review of Economic Studies 
